\title{
Implications of chemokine receptors and inflammatory lipids in cancer
}

This article was published in the following Dove Press journal:

ImmunoTargets and Therapy

24 December 2013

Number of times this article has been viewed

Johannes Rolin

Azzam A Maghazachi

Department of Physiology, Institute of Basic Medical Sciences, Faculty of Medicine, University of Oslo, Oslo, Norway
Correspondence: Johannes Rolin Department of Physiology, Institute of Basic Medical Sciences, Faculty of Medicine, University of Oslo, POB I 105 Blindern N-0317, Oslo, Norway Email johannes.rolin@medisin.uio.no
Abstract: Inflammatory lipids receive much attention due to their important biological activities. Knowledge of the chemokine system has also reached a level that makes it interesting in clinics, which prompted clinical trials into compounds manipulating chemokines or their receptors. However, little attention has been devoted to understand the relations between these two systems. Here, we will review the role of inflammatory lipids and chemokines in innate and adaptive immunity with an attempt to link the two systems and with emphasis on their importance in cancer development.

Keywords: chemokines, FTY720, HODE, linoleic acid, sphingosine 1-phosphate

\section{Introduction}

A fundamental aspect of leukocyte function is their migration. All leukocytes migrate from the bone marrow via the blood to reach their sites of action. This tightly regulated process involves multiple steps, of which chemokines only account for a few. After selectin-dependent rolling and integrin-dependent adhesion, chemokines induce polarization of the leukocytes as they change their shape and start crawling towards an extracellular gradient of the chemokines. ${ }^{1}$ Chemokine receptor signaling evokes cytoskeleton remodeling resulting in expansion of a lamellipodium in front and contraction in a myosin-dependent manner of the uropod at the back. Thus, by releasing molecules binding to the substrate below, cells move through tissues. As they navigate through the tissues, different chemokines and adhesion molecules in the microenvironment help in localizing various subsets of cells depending on their expression patterns of chemokine receptors.

\section{Chemokines and chemokine receptors}

Chemokines are important in health and disease as they orchestrate the infiltration of leukocytes. ${ }^{2}$ These molecules are divided into four subfamilies based on the position of the cysteine residue in the amino terminal end of the molecules; these are known as $\mathrm{CXC}$ or $\alpha$, $\mathrm{CC}$ or $\beta, \mathrm{C}$ or $\gamma$, and $\mathrm{CX}_{3} \mathrm{C}$ or $\delta$ chemokines. Chemokines and their receptors are also classified based on their functions as inflammatory chemokines or inflammatory chemokine receptors, or they are classified based on house-keeping functions that are involved in the circulation and homing of cells under physiological conditions. ${ }^{3}$ All chemokine receptors activate heterotrimeric $\mathrm{G}$ proteins and various intracellular signaling pathways. ${ }^{4}$

\section{Inflammatory lipids in innate immunity}

Lipids are important second messengers and much is yet to be known about their complex biology. We will focus here on the current knowledge of lipids and chemokines in inflammation, with an emphasis on cancer. 


\section{Lysophospholipids}

Among the lysophospholipids, sphingosine 1-phosphate (S1P) is one of the most extensively studied; it binds heptahelical receptors coupled to heterotrimeric $G$ proteins ${ }^{5}$ and constitutes a major part of serum and plasma. ${ }^{6,7} \mathrm{We}$ recently reviewed its impact on cancer microenvironment. ${ }^{8} \mathrm{~S} 1 \mathrm{P}$ is a multifunctional lipid present in high concentrations up to the micromolar range in the serum and it regulates many cell responses, such as cell proliferation, apoptosis, cell differentiation and migration, as well as immunological responses. ${ }^{7,9,10}$ It is generated from sphingolipids, which are essential plasma membrane lipids concentrated in liquid-ordered domains, commonly known as lipid rafts. ${ }^{11}$ S1P can be rapidly metabolized following stimulation of various plasma membrane receptors through the activation of an enzymatic cascade. This pathway has been denoted the sphingomyelin cycle, due to the fact that, for all the steps, reverse reactions may take place catalyzed by specific enzymes such as S1P phosphatases, ceramide synthase, and sphingomyelin synthase.

$\mathrm{S} 1 \mathrm{P}$ is synthesized by most cells, but, due to intracellular degradation by S1P lyase and S1P phosphatase-induced dephosphorylation, its level in tissues is low. ${ }^{12-15}$ The exception is blood with low micromolar levels of this lipid mainly contributed by erythrocytes. In the lymph, the S1P levels are in the hundred nanomolar range. ${ }^{16,17}$ Serum protein partners might have a role in determining the uptake and intracellular degradation of S1P as free S1P and S1P bound to serum albumin are more susceptible to degradation than when bound to lipoproteins such as high-density lipoprotein. ${ }^{18} \mathrm{Also}$, the concentration gradient between blood and tissues may be ablated by inhibition of S1P lyase activity, resulting in increased levels of S1P in tissues. ${ }^{17}$ There are reasons to believe that the lymph S1P, as well as its plasma level, is regulated by the endothelium. Secretion of the lipid from these cells is increased by the physiological stimulus of shear stress, ${ }^{19}$ but that is not the case for platelets ${ }^{16,19}$ nor mast cells. ${ }^{20}$

The direct actions of S1P may be exerted via two different mechanisms. Either via the extracellular S1P receptors or via intracellular modes of action..$^{21,22}$ The membrane bound receptors for S1P have been cloned, and were first linked to differentiation of endothelial cells. They were therefore named endothelial differentiation gene ${ }^{23}$ but renamed once it was realized that the ligand for the receptor family was S1P. ${ }^{24}$ Thus, they are now known as S1PR1, S1PR2, S1PR3, S1PR4, and S1PR. The receptors are expressed in different patterns through the immune system. ${ }^{11}$ Dendritic cells express all five receptors ${ }^{25,26}$ and human natural killer (NK) cells express
mRNA for all receptors except for S1PR2. ${ }^{27}$ All five receptors signal through G-protein coupled receptors, but differ in downstream effects. ${ }^{28,29}$ Initial findings of overexpression of sphingosine kinase 1 (SphK1) in fibroblasts capable of developing into tumors ${ }^{30}$ and enhanced SphK1 mRNA expression in solid tumors ${ }^{31,32}$ compared to normal tissues made S1P a possible target of research in the cancer field.

The main function of many of the S1P receptors is migration. ${ }^{27,33-35}$ Murine mature dendritic cells (mDCs), but not immature dendritic cells (iDCs), migrate towards S1P in a pattern correlated with the upregulation of S1PR and S1PR3 during maturation. ${ }^{36}$ This action is dependent on signaling through Rac/Cdc42 and Rho as blocking of these small GTPases results in a complete failure to migrate. The S1P receptor agonist fingolimod (FTY720) does not trigger migration of DCs ${ }^{36}$ leading to the proposition that part of the immune modulation accomplished by FTY720 may be caused by impaired DC migration.

Whereas low concentrations of S1P promote chemotaxis in a S1PR1 dependent manner, high concentrations seem to be inhibitory. ${ }^{33,37}$ An explanation for this inhibition may be downregulation of S1PR1 by high S1P concentrations. Blood concentrations of S1P are high and, therefore, this may be relevant in vivo during transit of cells in blood. ${ }^{11}$ In certain immune cells this concentration dependence is less evident, and in some cases the chemotactic response is associated with a particular stage of cell differentiation or cell activation, which leads to changes in receptor expression. This is the case for DCs as they mainly express S1PR1 in the immature state but upregulate S1PR3 upon maturation, which then may mediate their chemotactic response towards S1P. ${ }^{36}$ Interestingly, a similar regulatory capacity may exist for chemokine receptors through S1P receptor agonism as FTY720 at high doses significantly reduced renal expression of CCR (CC chemokine receptor) $1, \mathrm{CCR} 2$, and CCR5. ${ }^{38} \mathrm{In}$ this study of partly nephrectomized rats, CCL (CC motif ligand) 2/MCP-1 gene expression as well as plasma concentrations of the proinflammatory cytokines IFN(interferon) $-\gamma$, TNF (tumor necrosis factor)- $\alpha$, IL (interleukin)-6, IL-12 and CCL5/RANTES (regulated on activation, normal T-cell expressed and secreted) were also reduced. The effect may have been mediated by S1PR2 through $G_{\alpha q}$ and Rac1dependent signaling pathways. ${ }^{39}$

The cross talk among chemokines and the S1P system is evident in the study showing that FTY720 stimulated migration towards the lymph nodes is dependent on the CCR7 ligands CCL19 and CCL21. ${ }^{40}$ For FTY720 enhanced migration in lymphoid compartments, additional chemokine 
receptors are at work as compared to the homeostatic state. ${ }^{41}$ In this study, Yopp et $\mathrm{al}^{41}$ showed that FTY720-stimulated migration of T-cells is dependent on CCR2, CCR5, CCR7, and CXCR4 in anatomically restricted compartments. Later, it was shown that overexpression of S1PR1 results in reduced expression of CXCR4 leading to tenfold reduction in migration of Jurkat cells or peripheral blood progenitor cells towards CXCL12/SDF (stromal cell-derived factor)- $1 \alpha$ and eightfold reduction in bone marrow homing, ${ }^{42}$ while $\mathrm{S} 1 \mathrm{P}$ receptor agonists may sensitize the cells for CXCR4 signaling via S1PR3. ${ }^{43}$ This is in line with in vivo and in vitro evidence of increased CXCR4 function in hematopoietic progenitor cells, where activation of $\mathrm{S} 1 \mathrm{P}$ receptors by FTY720 modulated the effects of CXCL12/SDF- $1 \alpha .{ }^{44}$ Not only the S1P receptors are important in this respect, as disruption of the S1P gradient towards blood as well as desensitization of its receptors reduced egress of immature progenitors in the steady state due to inhibition of CXCL12/ SDF- $1 \alpha$ release. $^{45}$ Functionally, the S1P-CXCR 4 cross talk mediates adhesion and transendothelial migration of myeloma cells through upregulation of their adhesion followed by CXCL12/SDF-1 $\alpha$ mediated transmigration. ${ }^{46}$ The FTY720 mediated lymphopenia also relies on chemokine receptors for the initial accumulation of cells in secondary lymphoid organs, as is evident by it being delayed in mice lacking CCR7 and significantly reduced in CXCR5 knockout mice ${ }^{47}$ hence, the sequestration of lymphoid cells in the secondary lymphoid organs does not appear to depend on CCR7 and CXCR5. ${ }^{47}$ Synergism at the second messenger level may explain this. As well as CXCL13/BLC, the ligand for CXCR5 and S1P stimulate the common activation pathway of tyrosine kinases Pyk2 and Rap, which are required for their induction of B-cell migration as well as adhesion to intercellular adhesion molecule 1 (ICAM-1) and vascular cell adhesion protein 1 (VCAM-1). ${ }^{48}$ This mechanism may also be important for maturation as splenic T-cell migration towards CCL19/MIP-3 $\beta$ and CXCL12/SDF-1 $\alpha$ is enhanced by $\mathrm{S} 1 \mathrm{P}$ receptor stimulation, while peripheral lymph node nonactivated and naïve T-cells require both chemokines and $\mathrm{S} 1 \mathrm{P}$ receptors stimulation. ${ }^{49}$

\section{The prostaglandins}

Prostaglandin E2 (PGE2) is notable for its many ways of interfering with white blood cell functions. By suppressing acute inflammatory functions of macrophages, granulocytes, naive Th1 and cytotoxic T-cells, as well as NK cells, while promoting Th2 or T regulatory responses, it greatly influences the immune response. By activating its receptor,
EP2, PGE2 increases intracellular levels of cAMP (cyclic adenosine monophosphate) in NK cells ${ }^{50}$ and limits their cytolytic function $^{50-52}$ as well as reducing IFN- $\gamma$ secretion induced by IL-12 and/or IL-18. ${ }^{53}$ Accordingly, macrophage phagocytosis ${ }^{54}$ and bacterial killing ${ }^{55}$ is inhibited.

In DCs, IL-12 production is abrogated while the secretion of IL-10 is increased, leading to IL-4/IL-5 producing Th2 cells. This prompts a Th2-skewness as well as blockage of the development of IL-18-induced CCR $7^{+} \mathrm{NK}$ cells that would otherwise home to the lymph nodes in order to secrete IFN- $\gamma$ and promote Th1 responses. ${ }^{56}$ The production of Th1 cytokine IFN- $\gamma$, but not Th 2 cytokines IL-4 and IL-5, in T-cells is also inhibited by PGE. ${ }^{57}$ Finally, the Th1suppressive effects are evident in innate immune cells as IL-12 production is suppressed in monocytes ${ }^{58}$ and DCs. ${ }^{59}$

The generally inhibitory impact of PGE2 on innate immunity is especially evident in the case of cancer. The development of DCs is redirected towards myeloid-derived suppressor cells - functionally diverse immature myeloid cells promoting cancer development and suppressing cytotoxic T-lymphocytes responses - when PGE2 is added to the standard regimen of monocyte development. ${ }^{60}$ The same was observed when DCs were generated in the presence of PGE2 produced by cancer cells as it leads to a tolerogenic M2 phenotype with low expression of costimulatory molecules and altered IL-12/IL-10 balance, which leads to poor capacity to stimulate T-cell proliferation and IFN- $\gamma$ production. ${ }^{61}$

PGE2 impact on DCs when already maturated from monocytes is a lot different from the general inhibitory effects on monocytes. For example, PGE2, when added to cultures supplied with IL- $\beta$ or TNF- $\alpha$, accelerates the maturation of DCs, elevating their expression of costimulatory molecules ${ }^{62}$ and making them superior in inducing IFN- $\gamma$ release from T-cells. Emphasizing the differential impact of PGE2 on DCs at various differentiation stages, PGE2 enhanced IL-12 secretion from DCs while it reduced the levels secreted from LPS-stimulated DCs. ${ }^{63,64}$

PGE2 is required for functionally activating monocyte derived DCs upon upregulation of CCR7. ${ }^{65,66}$ Recently, the mechanism for the upregulation of CCR7 was shown to be due to decreased endogenous secretion of the CCR7 ligand CCL19/MIP-3 $\beta$ by PGE2. This results in the capacity to migrate towards lymph node associated chemokines CCL19/MIP-3 $\beta$ or CCL21/MIP-3 $\alpha$, which is a prerequisite for T-cell priming. ${ }^{66}$ DCs treated with PGE2 also showed enhanced expression of CCR7 and migration towards its ligands, while they were weak secretors of CCL19/MIP-3 $\beta$ and, hence, unable to attract naïve T-cells. ${ }^{67}$ 
PGE2 enhances production of interleukin 8 (CXCL8/ IL- 8$)^{68}$ and CCL2/MCP- $1{ }^{69}$ and is necessary for the migration of human DCs, ${ }^{70}$ and thus for the recruitment of cells of the innate immune system. However, CCR5 expression on monocytes and macrophages is blocked. ${ }^{71}$ Similarly, the functions of CCL5 and CXCR $3^{72}$ are also blocked, thus impeding the potential for NK-DC cross talk ${ }^{73}$ while at the same time attracting $\mathrm{T}$ regulatory cells. ${ }^{74}$ PGE2 is important as well for the production of CXCL12/SDF-1 $\alpha$, the expression of its receptor, CXCR4, on myeloid-derived suppressor cells, ${ }^{75}$ and, consequently, for the recruitment of these cells towards ovarian cancer sites. It even increases tumor growth through increased angiogenesis via the induction of CXCL1/GRO- $\alpha$ expression. ${ }^{76}$ Finally, emphasizing the importance of PGE2 in DC development, replacement of PGE2 $2^{77,78}$ and suppression of cyclooxygenase $2^{79,80}$ enhances the immunogenic and therapeutic activity of cancer vaccines. On the other hand, a recent knockout study of PGE-1 synthase in mice did not affect maturation or migration of DCs, suggesting that further research is needed in this field. ${ }^{81}$

\section{Relevance to cancer}

The importance of chemokines in cancer was established in early 1980s as MCP-1/CCL2 was identified in cultures of tumor cell lines. ${ }^{82}$ Knowledge of the important contributions in embryology and physiology has been followed by substantial research on the implications for cancer development and treatment.
Allavena et $\mathrm{a}^{83}$ reviewed the role of chemokines in cancer related inflammation, dividing the connection between chemokines and cancer related inflammation into two pathways: 1) the oncogene-driven intrinsic pathway that triggers the inflammatory cascade; and 2) the leukocyte-driven extrinsic pathway establishing inflammatory conditions, thus increasing cancer risk. Lazennec and Richmond ${ }^{84}$ provided further insights into the importance of chemokine receptors in this field.

In order to translate the implications of lipids through chemokines and their receptors to the different steps of cancer pathophysiology, we provide a stepwise model (Figure 1). In this model, seven key steps at which inflammatory lipids and chemokines play important roles are highlighted: 1) the adhesion and rolling of leukocytes as a first step in shaping the inflammatory milieu around cancer cells; 2) the transmigration of cancer cells through the vascular endothelium; 3 ) the impact of the tumor microenvironment on the leukocytes, implicating functional maturation towards anti- or pro-cancerous phenotypes; 4) the retention of leukocytes, mediated via the mechanisms described in step 3; 5) in malignant transformation. As the first step in cancerogenesis, this is the process by which normal tissue resident cells undergo genetic changes to become cancerous cells - at this point, chemokines do not play any major role, but we will touch upon how S1P and PGE2 do; 6) growth and development of a solid tumor; and 7) dissemination of cancer cells, which is highly dependent on the expression of chemokine receptors.

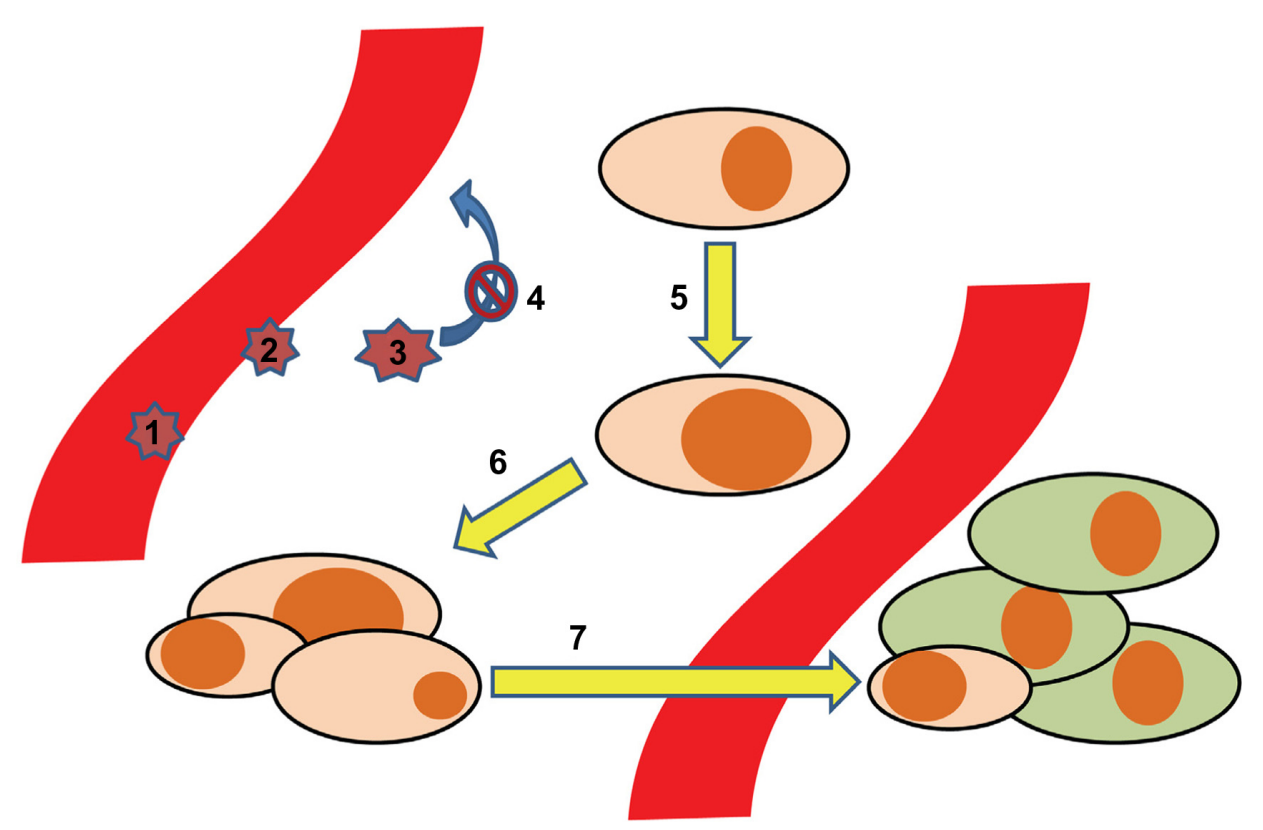

Figure I Development of tumor metastases aided by the chemokine system. The process of tumor dissemination is depicted in seven steps: I. Adhesion/rolling of leukocytes. 2. Transmigration of leukocytes. 3. Maturation of leukocytes. 4. Retention of leukocytes 5. Malignant transformation. 6. Malignant growth. 7. Metastases. 
Steps 1-4: Recruitment of leukocytes subsets (steps 1 and 2), followed by maturation of the cells into protumoral phenotypes (step 3), is an important process related to the function of chemokines. In this respect, Negus et al described the involvement of leukocytes in ovarian cancer stroma. ${ }^{85}$ By immunohistochemical analysis of epithelial ovarian tumor biopsies, they determined the content of leukocyte subsets. CD68 ${ }^{+}$macrophages accounted for 3,700 cells $/ \mathrm{mm}^{3}$, $\mathrm{CD}^{+} / \mathrm{CD} 45 \mathrm{RO}^{+} \mathrm{T}$-cells for 2,200 cells $/ \mathrm{mm}^{3}$, and NK cells, B-cells, and mast cells between zero and 200 cells $/ \mathrm{mm}^{3}$. There was a correlation between $\mathrm{CD} 8^{+} \mathrm{T}$-cells and numbers of cells expressing CCL2/MCP-1 and CCL5/RANTES. Further, a correlation between numbers of macrophages and the numbers of cells expressing CCL2/MCP-1 led to the suggestion that CCL2/MCP-1 may be responsible for leukocyte infiltration into ovarian carcinomas, ${ }^{85}$ and that epithelial cells are the major source of CCL2/MCP-1 ${ }^{86}$ Subsequently, in culture with tumor cells, the $\mathrm{CD} 14^{+} \mathrm{CD} 16^{-}$subset of monocytes increased the expression of CCR $2,{ }^{87}$ trapping them inside the cancer microenvironment. In this milieu, the same monocyte subset also increased its expression of CXCR1, CXCR2, and CXCR $4 .{ }^{87}$ The change was associated with enhanced migration towards CXCL8/IL-8 for the CXCR1 and CXCR2 expressing cells and towards stromal cell-derived factor-1 (CXCL12/SDF-1 $\alpha$ ) for the CXCR4 expressing ones. This reflects the importance of chemokine receptors in functionally programming the different monocyte subsets, as they express different chemokine receptors.

An example of how differences in the tumor microenvironment affects leukocyte chemokine expression comes from ovarian cancer. While CCR 1 and CCR5 are the only $\mathrm{CC}$ chemokine receptors that are consistently expressed in ovarian tumors, leukocytes in ascites of advanced ovarian cancer show expression patterns of chemokine receptors comparable to that which is found in peripheral blood. This has been proposed to be related to the microenvironment in which these cells are found, characterized by differential concentration levels of chemokines and cytokines, but also physiological factors such as hypoxia. ${ }^{85,88,89}$ Importantly, CCR2 is downregulated on tumor cells associated with macrophage phenotypes responding to local TNF- $\alpha$ production, which was suggested to serve as a mechanism to arrest and retain recruited macrophages (step 4).

The tumor chemokine microenvironment is further notable in that it is suppressive of specific anticancer responses. Exposure of macrophages to this milieu leads to their maturation into type-2 macrophages, or tumor-associated macrophages..$^{90}$ Their release of IL-10 and TGF- $\beta$ as well as CCL2/MCP-1 polarizes the immune response towards Th2, thus inhibiting macrophage and $\mathrm{CD} 8^{+} \mathrm{T}$-cell killing of cancer cells. In ovarian cancer, tumor cell production of CXCL12/SDF-1 $\alpha$ reduces immunity by attracting and protecting CXCR4-expressing plasmacytoid DCs but not myeloid DCs, hence weakening immunity. ${ }^{91}$ Emphasizing the importance of the chemokine system as a pro-cancerous mediator, data from mouse models suggest that the net effect may be the promotion of growth, angiogenesis, apoptosis, and metastasis..$^{92-94}$

Other observations indicate that it may be a matter of balancing pro- and anti-cancerous effects. This seems to be most important regarding angiogenesis, ${ }^{95}$ including human non-small-cell lung carcinoma, in which the ratio of glutamic acid-leucine-arginine to non-acid-leucine-arginine CXC chemokine expression is high, and in a severe combined immunodeficiency (SCID) mouse model where neutralization of endogenous tumor-derived CXCL8/IL-8 could inhibit tumor growth and metastasis by about $50 \%$ through a decrease in tumor-derived vessel density without directly affecting tumor cell proliferation. An interesting perspective is studies of D6 and the Duffy antigen, which are involved in post inflammatory clearance of chemokines, ${ }^{96}$ as they are related to general protection from cancer. ${ }^{97,98}$

Step 5 describes the malignant transformation. The chemokines do not directly play a major role at this point, however S1P and PGE2 do. S1P is regarded a prosurvival lipid due to its involvement in many of the processes implicated in the shaping of a favorable tumor microenvironment. ${ }^{8}$ Concerning the malignant transformation specifically, overexpression of sphingosine kinase 1 (SK1) - one of the two kinases that catalyze S1P - resulted in tumor formation in 3 T3 fibroblast ${ }^{30,99}$ while its deletion resulted in reduced head and neck squamous cell carcinogenesis. ${ }^{100}$ Very recent developments in the field suggest that SK interaction with oncogenes is critical in early development of cancer, as was recently reviewed. ${ }^{101}$

In the case of colon cancer, S1P and SK1 both independently stimulate the expression of cyclooxygenase 2 , leading to increased PGE2 levels. ${ }^{102}$ In this study, while $75 \%$ of the rat colon adenocarcinomas stained strongly positive for SK1, none of the normal epithelium samples did. The same group also linked the expression of the PGE2 receptor EP1 to colon cancer development as its knockdown reduced cancer incidence. ${ }^{103}$

In step 6, we describe the axis of another chemokine/ chemokine receptor in terms of enhancing cell growth. ${ }^{104}$ CXCR2 inhibits growth; its knockout reduces senescence 
(inability of division) that is oncogene-induced as well as replication-induced ${ }^{105}$ while CXCR2 overexpression leads to premature senescence. CXCL1/GRO- $\alpha$, the ligand for CXCR1 and CXCR2, also serves to reprogram cancerassociated stromal fibroblasts to a senescent protumorigenic state in ovarian cancer. ${ }^{106}$ Hence, CXCR2 and its ligands are regarded as gate keepers of tumor growth by increasing senescence. ${ }^{84} \mathrm{CXCR} 2$ also enhances neoangiogenesis and leukocyte infiltration, ${ }^{104}$ suggesting a function in establishing a sustainable tumor microenvironment rather than uncontrolled growth.

In the last step, we describe the process of dissemination, which is caused by cells traveling through the blood stream to reside in various tissues. These cells are a lot more susceptible to the effects of cytostatic drugs, which is promising in therapeutic terms. The consensus is that the gradients towards which the cancer cells migrate are generated by tissue resident cells, ${ }^{107}$ but a more autonomous role has been suggested. It implicates an autocrine mechanism by which cancer cells generate their own chemokine gradient, which has been described for CCL19/MIP-3 $\beta$ and CCL21/MIP-3 $\alpha{ }^{108}$
Some examples of chemokine directed dissemination are the chemokine receptor/chemokine axes CXCL12-CXCR4, CCL19-CCR7 or CCL21-CCR7, and CCL27-CCR10, which are associated with metastasis to bone, lymph nodes, and skin, respectively. ${ }^{107}$ Recent studies further link $\mathrm{CX}_{3} \mathrm{CR} 1$ expressed in pancreatic ductal adenocarcinoma cells to migration towards $\mathrm{CX}_{3} \mathrm{CL} 1 /$ fraktalkine produced by neurons and nerve fibers. ${ }^{109}$ Melanoma cells expressing CCR9 metastasize to the small intestine ${ }^{110}$ and non-melanoma cells expressing CXCR2 spread to the lungs. ${ }^{111}$ Finally, CCR7 aids cells in migrating into the lymph nodes and CXCR4 into distant organs. ${ }^{104}$ Based on this, there is a reason to believe that any small effect on the cancer microenvironment that may lead to alteration of the expression levels of these receptors may be of vital importance for clinical end points in cancer.

\section{Future perspectives}

In this review, we attempted to link two complicated systems (ie, chemokines and inflammatory lipids) and to explain their roles in cancer (Figure 2). We highlighted the importance of chemokine receptor CCR2, which binds CCL2/MCP-1 as

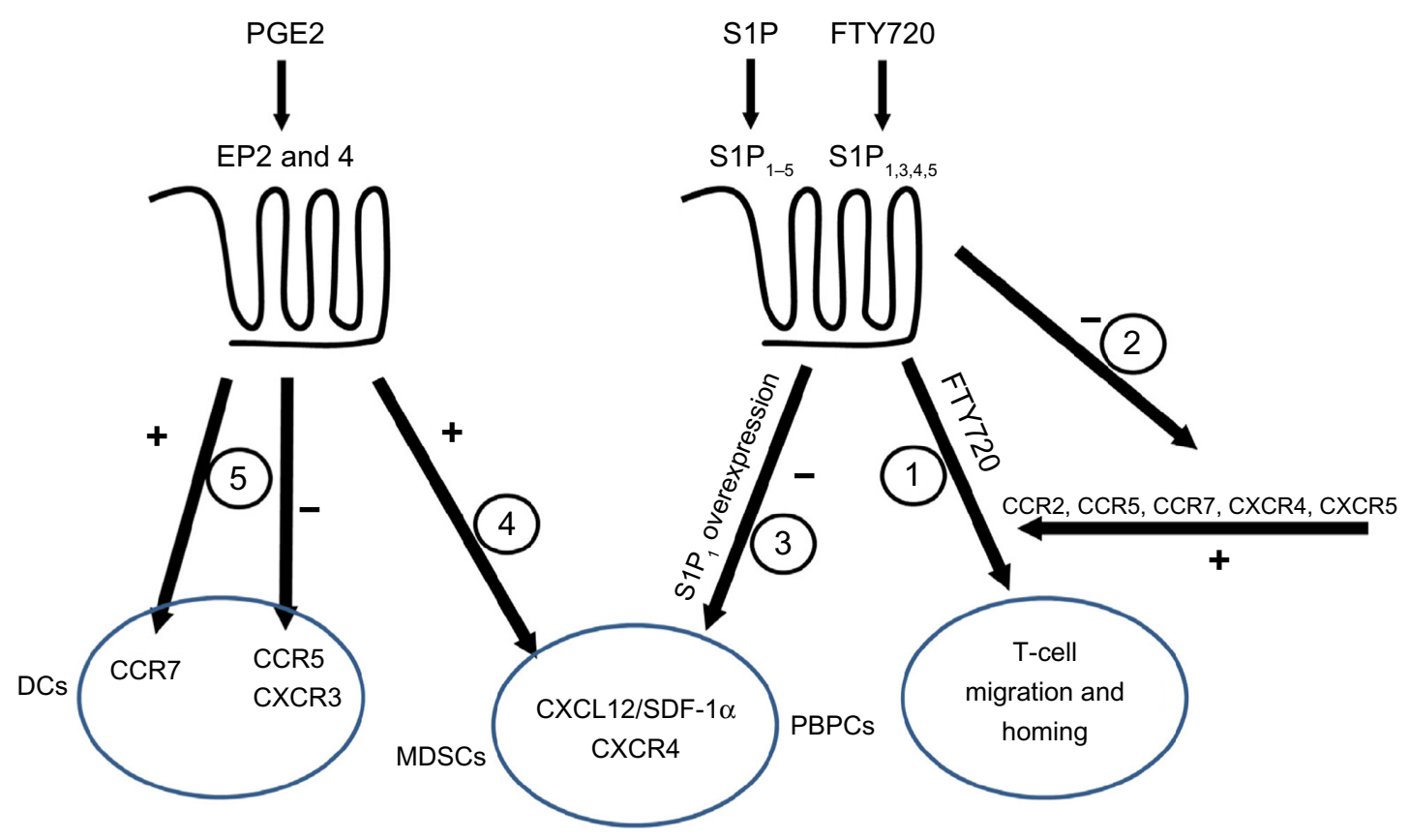

Figure 2 Interactions among chemokines and inflammatory lipids.

Notes: Both chemokines and inflammatory lipids receptors are coupled to G proteins. SIPI binds SIP $1-5$ FTY720 binds SIP 134, and PEG2 binds EP2 and EP4. Activity I: CCR2, CCR5, and CCR7, as well as CXCR4 and CXCR5, contribute to the effect of FTY720-induced homing of lymphocytes. Activity 2: FTY720 through SIP receptor agonism reduced the expression of CCRI, CCR2, and CCR5 in renal parenchyma. Activity 3: Overexpression of SIP, inhibits the migratory effect of CXCLI2/ SDF-I $\alpha$ for peripheral blood progenitor cells, and this effect is reduced upon FTY720 treatment due to downregulation of SIP, Activity 4: The expression of CXCR4, as well as the secretion of CXCLI2/SDF-I $\alpha$, is increased by PGE2 on myeloid derived suppressor cells, leading to their recruitment into tumor growth sites. Activity 5: PGE2 is a prerequisite for the expression of CCR7 in monocyte derived DCs, and it enhances their migration towards lymph node associated chemokines CCLI9/MIP-3/ or CCL2I/ MIP-3 $\alpha$. However, the expression of CCR5 and CXCR3 in monocytes and macrophages is blocked, impeding natural killer cell-DC's cross talk.

Abbreviations: PGE2, Prostaglandin E2; EP, prostaglandin E receptor; DCs, dendritic cells; CCR, CC chemokine receptor; CXCR, CXC chemokine receptor; SDF, stromal cell-derived factor; MDSCs, myeloid derived supressor cells; PBPCs, peripheral blood progenitor cells; SIP, sphingosine I-phosphate. 
responsible for attracting leukocytes that mature into procancerous cells inside the malignant growth site. In the mouse model of pancreatic cancer, CCR2 antagonism decreased metastasis of the cancer cells. ${ }^{112}$ On the other hand, the antagonists of CXCR2 are beneficial in a combined therapy regiment with oxaliplatin for preclinical colon cancer model. ${ }^{113}$ This knowledge of the chemokine system can therefore be utilized to prevent dissemination of cancer cells. This is shown to be possible in a mouse model of ovarian cancer where blockade of CXCL12-CXCR4 axis resulted in multiple effects including decreased dissemination of tumor cells corroborated with prolonged survival. ${ }^{114}$ Further, this has implications with regard to how the knowledge of the chemokine system can be applied to the inflammatory lipids. As indicated above, PGE2 and FTY720 may sensitize CXCR4 signaling, while T-cell migration initiated by FTY720 depends on CXCR4, CCR2, CCR5, and CCR7. This raises a question during the clinical use of FTY720 regarding the implications of systemic alterations in physiologically important systems. The adverse effects of long time treatment are difficult to foresee, but the increased risk of skin cancer upon FTY720 treatment, ${ }^{115}$ as seen in many in vitro studies, raises serious concerns. Similar problems arise with PGE-2, though the adverse effects for this molecule are well known. Nonsteroidal anti-inflammatory drugs, the inhibitors of the cyclooxygenases important for PGE-2 production, are feared for their gastrointestinal and cardiovascular side effects. Hence, in light of the general inhibitory effects of PGE-2 on innate immunity, preventing normal activation while inducing pro-cancerous phenotypes like MDSC and tumor-associated macrophages, emphasis should be on developing novel pharmacological approaches to limit the effects of PGE-2, other inflammatory lipids, and chemokines in cancer microenvironment.

\section{Disclosure}

The authors report no conflicts of interest in this work.

\section{References}

1. Mañes S, Gómez-Moutón C, Lacalle RA, Jiménez-Baranda S, Mira E, Martínez-A C. Mastering time and space: immune cell polarization and chemotaxis. Semin Immunol. 2005;17:77-86.

2. Raman D, Sobolik-Delmaire T, Richmond A. Chemokines in health and disease. Exp Cell Res. 2011;317:575-589.

3. Maghazachi AA. Role of chemokines in the biology of natural killer cells. Curr Top Microbiol Immunol. 2010;341:37-58.

4. Maghazachi AA. Insights into seven and single transmembrane-spanning domain receptors and their signaling pathways in human natural killer cells. Pharmacol Rev. 2005;57:339-357.

5. Oz-Arslan D, Rüscher W, Myrtek D, et al. IL-6 and IL-8 release is mediated via multiple signaling pathways after stimulating dendritic cells with lysophospholipids. J Leukoc Biol. 2006;80:287-297.
6. Pyne S, Pyne NJ. Sphingosine 1-phosphate signalling in mammalian cells. Biochem J. 2000;349:385-402.

7. Spiegel S, Milstien S. Sphingosine-1-phosphate: an enigmatic signalling lipid. Nat Rev Mol Cell Biol. 2003;4:397-407.

8. Rolin J, Maghazachi AA. Effects of lysophospholipids on tumor microenvironment. Cancer Microenviron. 2011;4:393-403.

9. Huwiler A, Kolter T, Pfeilschifter J, Sandhoff K. Physiology and pathophysiology of sphingolipid metabolism and signaling. Biochim Biophys Acta. 2000;1485:63-99.

10. Hait NC, Oskeritzian CA, Paugh SW, Milstien S, Spiegel S. Sphingosine kinases, sphingosine 1-phosphate, apoptosis and diseases. Biochim Biophys Acta. 2006;1758:2016-2026.

11. Rivera J, Proia RL, Olivera A. The alliance of sphingosine-1-phosphate and its receptors in immunity. Nat Rev Immunol. 2008;8:753-763.

12. Hannun YA, Obeid LM. Principles of bioactive lipid signalling: lessons from sphingolipids. Nat Rev Mol Cell Biol. 2008;9:139-150.

13. Mechtcheriakova D, Wlachos A, Sobanov J, et al. Sphingosine 1-phosphate phosphatase 2 is induced during inflammatory responses. Cell Signal. 2007;19:748-760.

14. Peest U, Sensken SC, Andréani P, Hänel P, Van Veldhoven PP, Gräler MH. S1P-lyase independent clearance of extracellular sphingosine 1-phosphate after dephosphorylation and cellular uptake. $J$ Cell Biochem. 2008;104:756-772.

15. Zhao Y, Kalari SK, Usatyuk PV, et al. Intracellular generation of sphingosine 1-phosphate in human lung endothelial cells: role of lipid phosphate phosphatase-1 and sphingosine kinase 1. J Biol Chem. 2007;282:14165-14177.

16. Pappu R, Schwab SR, Cornelissen I, et al. Promotion of lymphocyte egress into blood and lymph by distinct sources of sphingosine-1phosphate. Science. 2007;316:295-298.

17. Schwab SR, Pereira JP, Matloubian M, Xu Y, Huang Y, Cyster JG. Lymphocyte sequestration through S1P lyase inhibition and disruption of S1P gradients. Science. 2005;309:1735-1739.

18. Yatomi Y. Plasma sphingosine 1-phosphate metabolism and analysis. Biochim Biophys Acta. 2008;1780:606-611.

19. Venkataraman K, Lee YM, Michaud J, et al. Vascular endothelium as a contributor of plasma sphingosine 1-phosphate. Circ Res. 2008;102:669-676.

20. Olivera A, Mizugishi K, Tikhonova A, et al. The sphingosine kinasesphingosine-1-phosphate axis is a determinant of mast cell function and anaphylaxis. Immunity. 2007;26:287-297.

21. Alvarez SE, Harikumar KB, Hait NC, et al. Sphingosine-1-phosphate is a missing cofactor for the E3 ubiquitin ligase TRAF2. Nature. 2010;465:1084-1088.

22. Hait NC, Allegood J, Maceyka M, et al. Regulation of histone acetylation in the nucleus by sphingosine-1-phosphate. Science. 2009;325:1254-1257.

23. Hla T, Maciag T. An abundant transcript induced in differentiating human endothelial cells encodes a polypeptide with structural similarities to G-protein-coupled receptors. J Biol Chem. 1990;265: 9308-9313.

24. Spiegel S. Sphingosine 1-phosphate: a ligand for the EDG-1 family of G-protein-coupled receptors. Ann N Y Acad Sci. 2000;905: $54-60$.

25. Idzko M, Hammad $\mathrm{H}$, van Nimwegen $\mathrm{M}$, et al. Local application of FTY720 to the lung abrogates experimental asthma by altering dendritic cell function. J Clin Invest. 2006;116:2935-2944.

26. Maeda Y, Matsuyuki H, Shimano K, Kataoka H, Sugahara K, Chiba K. Migration of CD4 $\mathrm{T}$ cells and dendritic cells toward sphingosine 1-phosphate (S1P) is mediated by different receptor subtypes: S1P regulates the functions of murine mature dendritic cells via S1P receptor type 3. J Immunol. 2007;178:3437-3446.

27. Kveberg L, Bryceson Y, Inngjerdingen M, Rolstad B, Maghazachi AA. Sphingosine 1 phosphate induces the chemotaxis of human natural killer cells. Role for heterotrimeric $\mathrm{G}$ proteins and phosphoinositide 3 kinases. Eur J Immunol. 2002;32:1856-1864.

28. Sanchez T, Hla T. Structural and functional characteristics of S1P receptors. J Cell Biochem. 2004;92:913-922. 
29. Siehler S, Manning DR. Pathways of transduction engaged by sphingosine 1-phosphate through G protein-coupled receptors. Biochim Biophys Acta. 2002;1582:94-99.

30. Xia P, Gamble JR, Wang L, et al. An oncogenic role of sphingosine kinase. Curr Biol. 2000;10:1527-1530.

31. French KJ, Schrecengost RS, Lee BD, et al. Discovery and evaluation of inhibitors of human sphingosine kinase. Cancer Res. 2003;63: 5962-5969.

32. French KJ, Upson JJ, Keller SN, Zhuang Y, Yun JK, Smith CD. Antitumor activity of sphingosine kinase inhibitors. J Pharmacol Exp Ther. 2006;318:596-603.

33. Matloubian M, Lo CG, Cinamon G, et al. Lymphocyte egress from thymus and peripheral lymphoid organs is dependent on S1P receptor 1. Nature. 2004;427:355-360.

34. Graeler M, Goetzl EJ. Activation-regulated expression and chemotactic function of sphingosine 1-phosphate receptors in mouse splenic T cells. FASEB J. 2002;16:1874-1878.

35. Cinamon G, Matloubian M, Lesneski MJ, et al. Sphingosine 1-phosphate receptor 1 promotes $\mathrm{B}$ cell localization in the splenic marginal zone. Nat Immunol. 2004;5:713-720.

36. Czeloth N, Bernhardt G, Hofmann F, Genth H, Forster R. Sphingosine1-phosphate mediates migration of mature dendritic cells. J Immunol. 2005; 175:2960-2967.

37. Dorsam G, Graeler MH, Seroogy C, Kong Y, Voice JK, Goetzl EJ. Transduction of multiple effects of sphingosine 1-phosphate (S1P) on $\mathrm{T}$ cell functions by the S1P1 G protein-coupled receptor. J Immunol. 2003;171:3500-3507.

38. Schaier M, Vorwalder S, Sommerer C, et al. Role of FTY720 on M1 and M2 macrophages, lymphocytes, and chemokines in 5/6 nephrectomized rats. Am J Physiol Renal Physiol. 2009;297:F769-F780.

39. Kawata T, Ishizuka T, Tomura H, et al. Sphingosine 1-phosphate inhibits migration and RANTES production in human bronchial smooth muscle cells. Biochem Biophys Res Commun. 2005;331:640-647.

40. Honig SM, Fu S, Mao X, et al. FTY720 stimulates multidrug transporterand cysteinyl leukotriene-dependent $\mathrm{T}$ cell chemotaxis to lymph nodes. J Clin Invest. 2003;111:627-637.

41. Yopp AC, Fu S, Honig SM, et al. FTY720-enhanced T cell homing is dependent on CCR2, CCR5, CCR7, and CXCR4: evidence for distinct chemokine compartments. J Immunol. 2004;173:855-865.

42. Ryser MF, Ugarte F, Lehmann R, Bornhauser M, Brenner S. S1P(1) overexpression stimulates $\mathrm{S} 1 \mathrm{P}$-dependent chemotaxis of human CD34+ hematopoietic progenitor cells but strongly inhibits SDF-1/ CXCR4-dependent migration and in vivo homing. Mol Immunol. 2008;46:166-171.

43. Walter DH, Rochwalsky U, Reinhold J, et al. Sphingosine-1-phosphate stimulates the functional capacity of progenitor cells by activation of the CXCR4-dependent signaling pathway via the S1P3 receptor. Arterioscler Thromb Vasc Biol. 2007;27:275-282.

44. Kimura T, Boehmler AM, Seitz G, et al. The sphingosine 1-phosphate receptor agonist FTY720 supports CXCR4-dependent migration and bone marrow homing of human CD34+ progenitor cells. Blood. 2004; $103: 4478-4486$.

45. Golan K, Vagima Y, Ludin A, et al. S1P promotes murine progenitor cell egress and mobilization via S1P1-mediated ROS signaling and SDF-1 release. Blood. 2012;119:2478-2488.

46. García-Bernal D, Redondo-Muñoz J, Dios-Esponera A, et al. Sphingosine-1-phosphate activates chemokine-promoted myeloma cell adhesion and migration involving $\alpha 4 \beta 1$ integrin function. $J$ Pathol. 2013;229:36-48.

47. Muller G, Reiterer P, Hopken UE, Golfier S, Lipp M. Role of homeostatic chemokine and sphingosine-1-phosphate receptors in the organization of lymphoid tissue. Ann N Y Acad Sci. 2003;987: 107-116.

48. Durand CA, Westendorf J, Tse KW, Gold MR. The Rap GTPases mediate CXCL13- and sphingosine1-phosphate-induced chemotaxis, adhesion, and Pyk2 tyrosine phosphorylation in B lymphocytes. Eur J Immunol. 2006;36:2235-2249.
49. Yopp AC, Ochando JC, Mao M, Ledgerwood L, Ding Y, Bromberg JS. Sphingosine 1-phosphate receptors regulate chemokine-driven transendothelial migration of lymph node but not splenic $\mathrm{T}$ cells. J Immunol. 2005;175:2913-2924.

50. Goto T, Herberman RB, Maluish A, Strong DM. Cyclic AMP as a mediator of prostaglandin E-induced suppression of human natural killer cell activity. J Immunol. 1983;130:1350-1355.

51. Bankhurst AD. The modulation of human natural killer cell activity by prostaglandins. J Clin Lab Immunol. 1982;7:85-91.

52. Joshi PC, Zhou X, Cuchens M, Jones Q. Prostaglandin E2 suppressed IL-15-mediated human NK cell function through down-regulation of common gamma-chain. J Immunol. 2001;166:885-891.

53. Walker W, Rotondo D. Prostaglandin E2 is a potent regulator of interleukin-12- and interleukin-18-induced natural killer cell interferongamma synthesis. Immunology. 2004;111:298-305.

54. Aronoff DM, Canetti C, Peters-Golden M. Prostaglandin E2 inhibits alveolar macrophage phagocytosis through an E-prostanoid 2 receptor-mediated increase in intracellular cyclic AMP. J Immunol. 2004;173:559-565.

55. Canetti C, Serezani CH, Atrasz RG, White ES, Aronoff DM, PetersGolden M. Activation of phosphatase and tensin homolog on chromosome 10 mediates the inhibition of FcgammaR phagocytosis by prostaglandin E2 in alveolar macrophages. J Immunol. 2007;179: 8350-8356.

56. Mailliard RB, Alber SM, Shen H, et al. IL-18-induced CD83+CCR7+ NK helper cells. J Exp Med. 2005;202:941-953.

57. Snijdewint FG, Kalinski P, Wierenga EA, Bos JD, Kapsenberg ML. Prostaglandin E2 differentially modulates cytokine secretion profiles of human T helper lymphocytes. J Immunol. 1993;150: 5321-5329.

58. van der Pouw Kraan TC, Boeije LC, Smeenk RJ, Wijdenes J, Aarden LA. Prostaglandin-E2 is a potent inhibitor of human interleukin 12 production. $J$ Exp Med. 1995;181:775-779.

59. Kalinski P, Hilkens CM, Snijders A, Snijdewint FG, Kapsenberg ML. IL-12-deficient dendritic cells, generated in the presence of prostaglandin E2, promote type 2 cytokine production in maturing human naive T helper cells. J Immunol. 1997;159:28-35.

60. Obermajer N, Muthuswamy R, Lesnock J, Edwards RP, Kalinski P. Positive feedback between PGE2 and COX2 redirects the differentiation of human dendritic cells toward stable myeloid-derived suppressor cells. Blood. 2011;118:5498-5505.

61. Heusinkveld M, de Vos van Steenwijk PJ, Goedemans R, et al. M2 macrophages induced by prostaglandin E2 and IL-6 from cervical carcinoma are switched to activated M1 macrophages by CD4+ Th1 cells. J Immunol. 2011;187:1157-1165.

62. Jonuleit H, Kuhn U, Muller G et al. Pro-inflammatory cytokines and prostaglandins induce maturation of potent immunostimulatory dendritic cells under fetal calf serum-free conditions. Eur J Immunol. 1997;27:3135-3142.

63. Rieser C, Bock G, Klocker H, Bartsch G, Thurnher M. Prostaglandin E2 and tumor necrosis factor alpha cooperate to activate human dendritic cells: synergistic activation of interleukin 12 production. $J$ Exp Med. 1997;186:1603-1608.

64. Sharma S, Stolina M, Yang SC, et al. Tumor cyclooxygenase 2-dependent suppression of dendritic cell function. Clin Cancer Res. 2003;9:961-968.

65. Luft $\mathrm{T}$, Jefford $\mathrm{M}$, Luetjens $\mathrm{P}$, et al. Functionally distinct dendritic cell (DC) populations induced by physiologic stimuli: prostaglandin $\mathrm{E}(2)$ regulates the migratory capacity of specific DC subsets. Blood. 2002;100:1362-1372.

66. Scandella E, Men Y, Gillessen S, Forster R, Groettrup M. Prostaglandin E2 is a key factor for CCR7 surface expression and migration of monocyte-derived dendritic cells. Blood. 2002;100:1354-1361.

67. Muthuswamy R, Mueller-Berghaus J, Haberkorn U, Reinhart TA, Schadendorf D, Kalinski P. PGE(2) transiently enhances DC expression of CCR7 but inhibits the ability of DCs to produce CCL19 and attract naive T cells. Blood. 2010;116:1454-1459. 
68. Yu Y, Chadee K. Prostaglandin E2 stimulates IL-8 gene expression in human colonic epithelial cells by a posttranscriptional mechanism. J Immunol. 1998;161:3746-3752.

69. Nakayama T, Mutsuga N, Yao L, Tosato G. Prostaglandin E2 promotes degranulation-independent release of MCP-1 from mast cells. J Leukoc Biol. 2006;79:95-104.

70. Legler DF, Krause P, Scandella E, Singer E, Groettrup M. Prostaglandin E2 is generally required for human dendritic cell migration and exerts its effect via EP2 and EP4 receptors. J Immunol. 2006;176:966-973.

71. Zeidler R, Csanady M, Gires O, Lang S, Schmitt B, Wollenberg B. Tumor cell-derived prostaglandin E2 inhibits monocyte function by interfering with CCR5 and Mac-1. FASEB J. 2000;14:661-668.

72. Gustafsson K, Ingelsten M, Bergqvist L, Nystrom J, Andersson B, Karlsson-Parra A. Recruitment and activation of natural killer cells in vitro by a human dendritic cell vaccine. Cancer Res. 2008;68:5965-5971.

73. Van Elssen CH, Vanderlocht J, Oth T, Senden-Gijsbers BL, Germeraad WT, Bos GM. Inflammation-restraining effects of prostaglandin E2 on natural killer-dendritic cell (NK-DC) interaction are imprinted during DC maturation. Blood. 2011;118:2473-2482.

74. Muthuswamy R, Urban J, Lee JJ, Reinhart TA, Bartlett D, Kalinski P. Ability of mature dendritic cells to interact with regulatory $\mathrm{T}$ cells is imprinted during maturation. Cancer Res. 2008;68:5972-5978.

75. Obermajer N, Muthuswamy R, Odunsi K, Edwards RP, Kalinski P. PGE(2)-induced CXCL12 production and CXCR4 expression controls the accumulation of human MDSCs in ovarian cancer environment. Cancer Res. 2011;71:7463-7470.

76. Wang D, Wang H, Brown J, et al. CXCL1 induced by prostaglandin E2 promotes angiogenesis in colorectal cancer. J Exp Med. 2006;203:941-951.

77. Hokey DA, Larregina AT, Erdos G, Watkins SC, Falo LD Jr. Tumor cell loaded type-1 polarized dendritic cells induce Th1-mediated tumor immunity. Cancer Res. 2005;65:10059-10067.

78. Mailliard RB, Wankowicz-Kalinska A, Cai Q, et al. Alpha-type-1 polarized dendritic cells: a novel immunization tool with optimized CTL-inducing activity. Cancer Res. 2004;64:5934-5937.

79. Hahn T, Alvarez I, Kobie JJ, et al. Short-term dietary administration of celecoxib enhances the efficacy of tumor lysate-pulsed dendritic cell vaccines in treating murine breast cancer. Int J Cancer. 2006;118:2220-2231.

80. Haas AR, Sun J, Vachani A, et al. Cycloxygenase-2 inhibition augments the efficacy of a cancer vaccine. Clin Cancer Res. 2006;12: 214-222.

81. Monrad SU, Kojima F, Kapoor M, et al. Genetic deletion of mPGES-1 abolishes PGE2 production in murine dendritic cells and alters the cytokine profile, but does not affect maturation or migration. Prostaglandins Leukot Essent Fatty Acids. 2011;84:113-121.

82. Bottazzi B, Polentarutti N, Acero R, et al. Regulation of the macrophage content of neoplasms by chemoattractants. Science. 1983;220:210-212.

83. Allavena P, Germano G, Marchesi F, Mantovani A. Chemokines in cancer related inflammation. Exp Cell Res. 2011;317:664-673.

84. Lazennec G, Richmond A. Chemokines and chemokine receptors: new insights into cancer-related inflammation. Trends Mol Med. 2010;16:133-144.

85. Negus RP, Stamp GW, Hadley J, Balkwill FR. Quantitative assessment of the leukocyte infiltrate in ovarian cancer and its relationship to the expression of C-C chemokines. Am J Pathol. 1997;150:1723-1734.

86. Negus RP, Stamp GW, Relf MG, et al. The detection and localization of monocyte chemoattractant protein-1 (MCP-1) in human ovarian cancer. J Clin Invest. 1995;95:2391-2396.

87. Stec M, Baran J, Baj-Krzyworzeka M, et al. Chemokine receptors and chemokine production by CD34+ stem cell-derived monocytes in response to cancer cells. Anticancer Res. 2012;32:4749-4753.

88. Sica A, Saccani A, Bottazzi B, et al. Defective expression of the monocyte chemotactic protein-1 receptor CCR2 in macrophages associated with human ovarian carcinoma. J Immunol. 2000;164:733-738.
89. Grimshaw MJ, Balkwill FR. Inhibition of monocyte and macrophage chemotaxis by hypoxia and inflammation - a potential mechanism. Eur J Immunol. 2001;31:480-489.

90. Solinas G, Germano G, Mantovani A, Allavena P. Tumor-associated macrophages (TAM) as major players of the cancer-related inflammation. J Leukoc Biol. 2009;86:1065-1073.

91. Zou W, Machelon V, Coulomb-L'Hermin A, et al. Stromal-derived factor- 1 in human tumors recruits and alters the function of plasmacytoid precursor dendritic cells. Nat Med. 2001;7:1339-1346.

92. Orimo A, Gupta PB, Sgroi DC, et al. Stromal fibroblasts present in invasive human breast carcinomas promote tumor growth and angiogenesis through elevated SDF-1/CXCL12 secretion. Cell. 2005;121: 335-348.

93. Mantovani A, Savino B, Locati M, Zammataro L, Allavena P, Bonecchi R. The chemokine system in cancer biology and therapy. Cytokine Growth Factor Rev. 2010;21:27-39.

94. Mantovani A, Allavena P, Sozzani S, Vecchi A, Locati M, Sica A. Chemokines in the recruitment and shaping of the leukocyte infiltrate of tumors. Semin Cancer Biol. 2004;14:155-160.

95. Strieter RM, Burdick MD, Mestas J, Gomperts B, Keane MP, Belperio JA. Cancer CXC chemokine networks and tumour angiogenesis. Eur J Cancer. 2006;42:768-778.

96. Mantovani A, Bonecchi R, Locati M. Tuning inflammation and immunity by chemokine sequestration: decoys and more. Nat Rev Immunol. 2006;6:907-918.

97. Vetrano S, Borroni EM, Sarukhan A, et al. The lymphatic system controls intestinal inflammation and inflammation-associated colon cancer through the chemokine decoy receptor D6. Gut. 2010;59: 197-206

98. Wang J, Ou ZL, Hou YF, et al. Enhanced expression of Duffy antigen receptor for chemokines by breast cancer cells attenuates growth and metastasis potential. Oncogene. 2006;25:7201-7211.

99. Le SE, Pchejetski D, Banno Y, et al. Overexpression of sphingosine kinase 1 is an oncogenic event in erythroleukemic progression. Blood. 2005;106:1808-1816.

100. Shirai K, Kaneshiro T, Wada M, et al. A role of sphingosine kinase 1 in head and neck carcinogenesis. Cancer Prev Res (Phila). 2011;4: 454-462.

101. Pyne S, Pyne NJ. New perspectives on the role of sphingosine 1-phosphate in cancer. Handb Exp Pharmacol. 2013;55-71.

102. Kawamori T, Osta W, Johnson KR, et al. Sphingosine kinase 1 is up-regulated in colon carcinogenesis. FASEB J. 2006;20: 386-388.

103. Kawamori T, Kitamura T, Watanabe K, et al. Prostaglandin E receptor subtype EP(1) deficiency inhibits colon cancer development. Carcinogenesis. 2005;26:353-357.

104. Raman D, Baugher PJ, Thu YM, Richmond A. Role of chemokines in tumor growth. Cancer Lett. 2007;256:137-165.

105. Acosta JC, O'Loghlen A, Banito A, et al. Chemokine signaling via the CXCR2 receptor reinforces senescence. Cell. 2008;133:1006-1018.

106. Yang G, Rosen DG, Zhang Z, et al. The chemokine growth-regulated oncogene 1 (Gro-1) links RAS signaling to the senescence of stromal fibroblasts and ovarian tumorigenesis. Proc Natl Acad Sci U S A. 2006; 103:16472-16477.

107. Ben-BaruchA. Organ selectivity in metastasis: regulation by chemokines and their receptors. Clin Exp Metastasis. 2008;25:345-356.

108. Shields JD, Fleury ME, Yong C, Tomei AA, Randolph GJ, Swartz MA. Autologous chemotaxis as a mechanism of tumor cell homing to lymphatics via interstitial flow and autocrine CCR7 signaling. Cancer Cell. 2007;11:526-538.

109. Marchesi F, Piemonti L, Fedele G, et al. The chemokine receptor CX3CR1 is involved in the neural tropism and malignant behavior of pancreatic ductal adenocarcinoma. Cancer Res. 2008;68: 9060-9069.

110. Amersi FF, Terando AM, Goto Y, et al. Activation of CCR9/CCL25 in cutaneous melanoma mediates preferential metastasis to the small intestine. Clin Cancer Res. 2008;14:638-645. 
111. Singh S, Varney M, Singh RK. Host CXCR2-dependent regulation of melanoma growth, angiogenesis, and experimental lung metastasis. Cancer Res. 2009;69:411-415.

112. Sanford DE, Belt BA, Panni RZ, et al. Inflammatory monocyte mobilization decreases patient survival in pancreatic cancer: a role for targeting the CCL2/CCR2 axis. Clin Cancer Res. 2013;19: 3404-3415.

113. Ning Y, Labonte MJ, Zhang W, et al. The CXCR2 antagonist, SCH527123 , shows antitumor activity and sensitizes cells to oxaliplatin in preclinical colon cancer models. Mol Cancer Ther. 2012;11:1353-1364.
114. Righi E, Kashiwagi S, Yuan J, et al. CXCL12/CXCR4 blockade induces multimodal antitumor effects that prolong survival in an immunocompetent mouse model of ovarian cancer. Cancer Res. 2011;71:5522-5534.

115. Cohen JA, Barkhof F, Comi G, et al. Oral fingolimod or intramuscular interferon for relapsing multiple sclerosis. N Engl J Med. 2010;362: $402-415$.

\section{Publish your work in this journal}

ImmunoTargets and Therapy is an international, peer-reviewed open access journal focusing on the immunological basis of diseases, potential targets for immune based therapy and treatment protocols employed to improve patient management. Basic immunology and physiology of the immune system in health, and disease will be also covered. In addition, the journal will focus on the impact of manage-

\section{Dovepress}

ment programs and new therapeutic agents and protocols on patient perspectives such as quality of life, adherence and satisfaction. The manuscript management system is completely online and includes a very quick and fair peer-review system, which is all easy to use. Visit http://www.dovepress.com/testimonials.php to read real quotes from published authors.

Submit your manuscript here: http://www.dovepress.com/immunotargets-and-therapy-journal 